\title{
NEUROSCIENCE
}

\section{Circuit breakers}

Salay, LD., Ishiko, N., and Huberman A.D. Nature 557, 183-189 (2018); Stagkourakis, S. et al. Nat. Neurosci. 21, 834-842 (2018)

Ever wonder what's going on in the minds of different mice? In two recent papers, researchers dissect the brain circuits behind common behaviors.

The first, published in Nature, considers how mice respond to threats. When something looms overhead, some mice will freeze in place in the hopes of passing unnoticed, while others will dart for the safety of a shelter; the boldest may rattle their tails at the unwelcome intruder. There are pros and cons to each response: exposed mice may find themselves a quick snack-or first into the hands of a waiting researcher or technician-while skittering away can be a waste of energy if the threat proves benign. What prompts these different reactions?

Using a marker called c-Fos that flags recently activated neurons, the researchers involved observed that a part of the brain called the ventral midline thalamus (vMT) lit up in mice reacting to an overhead stimulus. To tease out its role, they chemically turned the vMT off and on. In both cases, mice still froze or fled, but silencing the vMT eliminated any tail rattling while activating it prompted much more.

A closer look at the larger circuits involved pinpointed pathways connecting the vMT to the basolateral amygdala and the medial prefrontal cortex, both areas of the brain previously tagged to fear responses and anxiety. Activating the first circuit made the mice freeze, while activating the second increased tail-rattling and running behavior.

Though the threat cue is visual, the vMT is not directly involved in visual perception. Instead, it appears to influence arousal and affect an animal's internal state-activating the vMT prior to the stimulus prompted active responses. The vMT, the authors propose in the paper, is likely an integration point for sensory stimuli and internal state, which then biases the behavioral outcome.

A second study, published in Nature Neuroscience, looks at aggression and hierarchy establishment in male mice. Previous rodent work has narrowed in on regions in the brain that influence attack behavior; in the current paper, the researchers focused on one in particular: the hypothalamic ventral premammillary nucleus (PMv). They sorted a cohort of males into aggressive and non-aggressive groups and confirmed with c-Fos that PMv activation was greater in the former.

Using optogenetics to switch the nucleus on and off could aggravate or interrupt attack behavior in aggressive males (with no meaningful effect on the more docile animals). They could also manipulate established hierarchies. Working with male pairs, the researchers show that silencing the PMv in the dominant mouse while activating it in the submissive one could flip the roles in the hierarchy, an effect that could last for the duration of the 14-day trial.

\section{Ellen P. Neff}

Published online: 25 June 2018

https://doi.org/10.1038/s41684-018-0101-0

\section{nature research} EDITING SERVICE

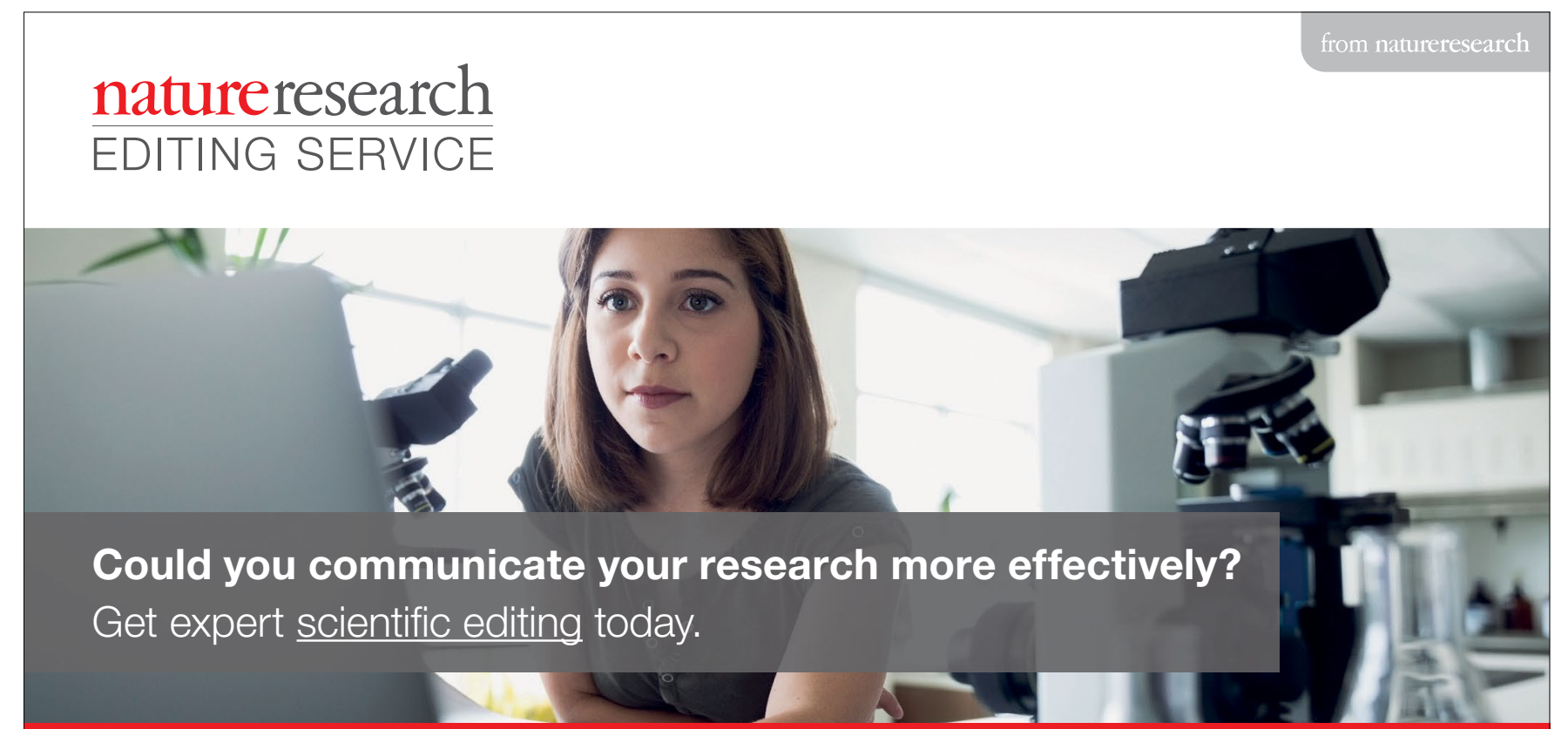

\section{Our editors understand what it takes to get published and can offer you expert advice to help optimise your research paper or grant proposal.}

